\section{Smaller samples, more data}

\section{By Kai-Jye Lou, Staff Writer}

Despite being broadly used for a variety of tasks in the clinic, proteomic analysis has limitations that impede its routine use in the analysis of clinical cancer specimens because techniques such as flow cytometry and western blot analysis require laborious preparation steps and large volumes of clinical samples. Researchers at Stanford University and Cell Biosciences Inc. are looking to change that with an automated protein analysis system, and they have developed the first clinically applicable assay for the technology. ${ }^{1}$

The assay, which can be analyzed using the biotech's newly launched CB1000 protein analysis system, showed that changes in mitogenactivated protein kinase 1 (MAPK1; ERK2) phosphorylation could be associated with responsiveness to cancer therapy.

In a paper in Nature Medicine, a research group led by Stanford's Dean Felsher used the assay to show that a decrease in monophosphorylated ERK2 could signal a response to Novartis AG's Gleevec imatinib in patients with chronic myelogenous leukemia (CML). The seven Gleevec responders had decreased levels of the monophosphorylated ERK2 isoform whereas two patients with resistant disease did not.

In a CML cell line, treatment with Gleevec for 24 hours produced a similar decrease in monophosphorylated ERK2 levels.

The difference in monophosphorylated ERK2 levels between responders and nonresponders was much less discernable when the researchers used fluorescence-activated cell sorting (FACS) and western blot analysis.

"The nanofluidic proteomic immunoassay allows us to assess treatment response at the level of protein expression," said Alice Fan, lead author on the Nature Medicine paper and a clinical instructor in the Division of Oncology at Stanford. "With current cancer drugs, it is difficult to quickly determine if a patient is responding to treatment because we usually have to wait several weeks to months before we can radiographically measure tumor metabolic activity or shrinkage."

Identifying signs of treatment response at the protein level could allow for the rapid assessment of patient responsiveness, said Felsher, who is an associate professor of medicine and oncology and leader of the molecular therapeutics program at Stanford and sits on the scientific advisory board at Cell Biosciences. If the assay indicates a drug is unlikely to have an effect, the result could be fewer unnecessary therapy cycles and a faster transition to other drugs.

\section{Automate the blot}

The nanofluidic assay described in the paper is designed for use with Cell Biosciences' automated protein analysis products-either CB1000 or its predecessor, the Firefly 3000 system. In both systems, proteins in a sample are separated by electrical charge, immobilized and then probed with a single antibody. A camera collects a raw signal that the system's software uses to generate quantitative results.

The initial separation of proteins by charge and use of a single antibody allows the system to detect and quantify phosphorylated protein isoforms.

According to David Hirschberg, director of the Human Immune Monitoring Center at Stanford, the systems essentially automate protein immunoblots and "allow you to do them in a high throughput manner. Furthermore, the results are highly reproducible and allow for quantification. Immunoblots allow you to detect proteins but do not readily allow you to quantify the results."

Walter Ausserer, VP of marketing at Cell Biosciences, said standard western blot analysis requires multiple antibodies to distinguish between protein isoforms within a sample. However, the use of multiple antibodies makes it difficult to accurately quantify and compare the amounts of each protein due to differences in antibody target affinity.

In addition to the ability to quantify and detect subtle changes in the expression of oncoproteins, the Cell Biosciences systems require much less protein than conventional methods. Using Firefly, Felsher's team needed only nanoliter volumes of clinical sample. The system was able to detect and quantify as little as 2 picograms of protein from a 4 nanoliter sample.

Ausserer said techniques like flow cytometry and mass spectrometry require samples containing 10,000 and 100,000 cells, respec-

tively. In contrast, the Cell Biosciences systems require only about 25 cells per test. "The ability to analyze smaller samples allows researchers to use less-invasive sample extraction techniques," he said.

"With the Firefly technology, we can use minimally invasive techniques to serially sample a tumor before and after we began treatment," Felsher told SciBX. "It is just not practical to take a surgical biopsy before and after treatment for the purposes of evaluating treatment response."

Fine needle aspirate biopsies are minimally invasive and safer than surgical biopsies and can extract cells from a broader range of cancer types. However, according to Fan, "a fine needle aspirate sample usually only provides you enough material for one analysis at the protein level using standard immunohistochemistry approaches. With the Firefly system, one can perform many analyses with the material from a single extraction."

Fan and Felsher were able to take clinical samples via fine needle aspirate biopsies and obtain results within a few hours, Hirschberg 
told SciBX. "This Firefly system has the potential to become a useful clinical tool, as it can analyze many very small patient samples in a short amount of time."

Fan did have a caveat: the use of small samples does increase the potential for sampling bias. "When you have the capacity to make a measurement using only a small number of cells, you need to make sure the cells in your sample are representative of what you mean to measure," she said. "A tumor, for example, could have a very heterogeneous distribution of cells."

Felsher also noted that "nothing can replace the advantage of being able to obtain a larger amount of tissue. But there are cases where this is not practical."

Fan thinks the Firefly and CB1000 systems will complement existing methods for analyzing clinical specimens, suggesting they can be paired with FACS analysis to obtain "more than double the amount of information from a sample."

Felsher said his group is now developing and validating the clinical applicability of additional assays for the Cell Biosciences systems. His group is also evaluating the system in additional tumor types and clinical settings and using it to identify new cancer biomarkers.
A patent application has been filed covering the disease and clinical response markers identified in the Nature Medicine paper. The work is available for licensing through the Stanford University Office of Technology Licensing.

Cell Biosciences holds multiple patents covering the technology platform used in its Firefly 3000 and CB1000 systems. The company markets multiple assay kits for its protein analysis systems, which include a kit that can be used to detect and quantify various ERK isoforms.

Lou, K.-J. SciBX 2(20); doi:10.1038/scibx.2009.814

Published online May 21, 2009

\section{REFERENCES}

1. Fan, A.C. et al. Nat. Med.; published online April 12, 2009; doi:10.1038/nm.1903

Contact: Dean W. Felsher, Stanford University, Stanford, Calif. e-mail: dfelsher@stanford.edu

\section{COMPANIES AND INSTITUTIONS MENTIONED}

Cell Biosciences Inc., Palo Alto, Calif.

Novartis AG (NYSE:NVS; SIX:NOVN), Basel, Switzerland Stanford University, Stanford, Calif. 